\title{
Expression profiling and bioinformatic analyses suggest new target genes and pathways for human hair follicle related microRNAs
}

Lara M. Hochfeld ${ }^{1,2}$, Thomas Anhalt ${ }^{1,2}$, Céline S. Reinbold ${ }^{3}$, Marisol Herrera-Rivero ${ }^{1,2}$, Nadine Fricker ${ }^{1,2}$, Markus M. Nöthen ${ }^{1,2}$ and Stefanie Heilmann-Heimbach ${ }^{1,2^{*}}$

\begin{abstract}
Background: Human hair follicle (HF) cycling is characterised by the tight orchestration and regulation of signalling cascades. Research shows that micro(mi)RNAs are potent regulators of these pathways. However, knowledge of the expression of miRNAs and their target genes and pathways in the human HF is limited. The objective of this study was to improve understanding of the role of miRNAs and their regulatory interactions in the human HF.

Methods: Expression levels of ten candidate miRNAs with reported functions in hair biology were assessed in HFs from 25 healthy male donors. MiRNA expression levels were correlated with mRNA-expression levels from the same samples. Identified target genes were tested for enrichment in biological pathways and accumulation in protein-protein interaction (PPI) networks.

Results: Expression in the human HF was confirmed for seven of the ten candidate miRNAs, and numerous target genes for miR-24, miR-31, and miR-106a were identified. While the latter include several genes with known functions in hair biology (e.g., ITGB1, SOX9), the majority have not been previously implicated (e.g., PHF1). Target genes were enriched in pathways of interest to hair biology, such as integrin and GnRH signalling, and the respective gene products showed accumulation in PPIs.

Conclusions: Further investigation of miRNA expression in the human HF, and the identification of novel miRNA target genes and pathways via the systematic integration of miRNA and mRNA expression data, may facilitate the delineation of tissue-specific regulatory interactions, and improve our understanding of both normal hair growth and the pathobiology of hair loss disorders.
\end{abstract}

Keywords: miRNA, mRNA, Gene regulation, Human hair biology, Correlation analysis

\section{Background}

The human hair follicle (HF) passes through cycles of active growth (anagen); regression (catagen); and rest (telogen). Each of these stages is tightly regulated, and is characterised by distinct changes in gene expression, cell proliferation, and differentiation $[1,2]$.

\footnotetext{
* Correspondence: sheilman@uni-bonn.de

${ }^{1}$ Institute of Human Genetics, University of Bonn, Sigmund-Freud-Str. 25,

53127 Bonn, Germany

${ }^{2}$ Department of Genomics, Life and Brain Center, University of Bonn,

Sigmund-Freud-Str. 25, 53127 Bonn, Germany

Full list of author information is available at the end of the article
}

Micro(mi)RNAs are short ( 20-25 nucleotides), noncoding RNAs, which influence gene expression by binding to target messenger(m)RNAs via a complementary seed region, which elicits mRNA degradation or transcriptional inhibition. In recent years, accumulating research data have indicated the importance of miRNAs as potent regulators of numerous developmental and pathobiological processes [3]. Several miRNAs have been implicated in hair biology, e.g., in the control of hair pigmentation, HF cycling, and keratinocyte differentiation [4-6]. For instance, miR-137 is reported to be responsible for coat colour determination in mice [5], while the 
inhibition of miR-31 in murine skin has been shown to result in accelerated anagen progression and abnormal hair shaft morphology [4]. A further study reported, a differential expression for four miRNAs (miR-106a, miR410, miR-221, miR-125b) in dermal papilla cells (DPCs) from the balding and non-balding scalp areas of eight patients with male pattern baldness (MPB) [7]. However, the majority of available data on the role of miRNAs in hair biology have been obtained from mouse or cell culture experiments, and knowledge of the genes and pathways that are targeted by these miRNAs in the human HF is limited. Such knowledge is essential in terms of understanding the relevance of miRNAs to human hair (patho-) biology.

The aims of the present study were to: 1) perform a systematic investigation of the expression of ten candidate miRNAs (miR-22, miR-24, miR-31, miR-106a, miR125b, miR-137, miR-205, miR-214, miR-221, miR-410) in human HF samples; 2) correlate these data with corresponding HF mRNA expression levels; and 3) test the identified target genes for enrichment in pathways and protein networks in order to delineate regulatory interactions in the human HF.

\section{Methods}

\section{Sample collection and nucleic acid extraction}

HF samples were collected from the frontal- and the occipital scalp areas of 25 volunteer healthy male donors of European descent (mean age 24.2 years \pm 1.6 ). RNA and miRNA were extracted from HF tissue using the miRNeasy Mini Kit and the RNeasy MinElute Cleanup Kit (Qiagen, Hilden, Germany). The quantity and quality of the extracted RNAs and miRNAs were tested on an ND-1000 spectrophotometer (Peqlab Biotechnologie, Erlangen, Germany) and a BioAnalyzer 2100 (Agilent Technologies, Waldbronn, Germany), respectively. Samples with an RNA concentration of $\geq 20 \mathrm{ng} / \mu \mathrm{l}$, an RNA integrity number (RIN) of $\geq 8$ and a miRNA concentration of $\geq 25 \mathrm{ng} / \mu \mathrm{l}$ were included in the microarray analysis.

\section{miRNA profiling}

MiRNA profiling of $\mathrm{n}=50$ samples (25 frontal, 25 occipital) was performed on the Affymetrix GeneChip miRNA 4.0 (Affymetrix, Santa Clara, CA) using a total of $250 \mathrm{ng}$ of $\mathrm{HF}$ miRNA. Poly(A) tailing and biotinylation were performed with the Affymetrix GeneChip Hybridization, Wash, and Stain Kit, in accordance with the manufacturer's instructions. After scanning, miRNA raw expression values were background subtracted, quantile normalised and $\log _{2}$-transformed using robust multi-array analysis (RMA) and detection above background (DABG) in the Affymetrix Expression Console ${ }^{\text {тм }}$ (Affymetrix Santa Clara, CA). A total of 48 samples from 24 individuals fulfilled all quality control criteria.
Candidate miRNAs were considered to be expressed if they were defined as 'present' in $\geq 80 \%$ of all samples.

\section{mRNA profiling}

Whole transcriptome profiling of the corresponding HF RNA samples was performed using the TotalPrep ${ }^{\mathrm{Tm}}-96$ RNA Amplification Kit and Illumina HT-12v4 Bead Arrays (Illumina Inc., San Diego, CA). Background subtracted expression intensities and detection $P$-values were exported from the Illumina GenomeStudio software. These were then quantile normalised and $\log _{2}$ transformed using the $\mathrm{R}$ package 'limma'. Only probes with all of the following four characteristics were taken into account: (i) a detection $P$-value of $<0.05$ (indicating significant expression above background) in at least $80 \%$ of the samples; (ii) a good or perfect probe quality; (iii) an annotated Entrez gene identifier, as reported in the Bioconductor package illuminaHumanv4.db [8]; and (iv) no single nucleotide polymorphism within the probe sequence (dbSNP Build 142). After filtering, a total of 10,029 expression probes, corresponding to 8,210 gene symbols, remained for the correlation analysis.

\section{Selection of candidate miRNAs}

Candidate miRNAs were selected based on the results of a comprehensive PubMed literature search for the role of miRNAs in HF biology. A total of ten candidate miRNAs (miR-22, miR-24, miR-31, miR-106a, miR-125b, miR-137, miR-205, miR-214, miR-221, and miR-410) were selected for investigation in the human HF (PMIDs: 26020521, 20522784, 21362569, 21967250, 22847819, 23974039, 24232098, and 25422376). These miRNAs were represented by 21 expression probes on the Affymetrix miRNA4.0 array (Table 1).

\section{Target gene identification}

To identify targets genes, mean miRNA and mRNA expression levels were calculated from the frontal and occipital sample of each of the final 24 participants. The expression levels of 10,029 mRNA probes and seven expressed candidate miRNAs which were represented by 14 mature miRNA forms were correlated using the Pearson correlation analysis method [9]. The respective correlation coefficients $(r)$ were computed and the resulting $P$-values were then corrected for multiple testing using Benjamini-Hochberg correction $\left(P_{\text {adj }}\right)$. All mRNAs with a significant correlation $\left(P_{\text {adj }}<0.01\right)$ to a candidate miRNA were assumed to be target genes. To exclude correlations driven by differential expression between frontal and occipital samples, the correlation trend was confirmed via single-tissue analysis (Additional file 1: Table S1, Additional file 2: Figure S1). 
Table 1 Overview of selected candidate miRNAs: Previously reported role(s) in hair biology and expression status of the analysed miRNAs in the human hair follicle (HF)

\begin{tabular}{|c|c|c|c|c|c|}
\hline Candidate miRNA & Reported role in hair biology & Reference & $\begin{array}{l}\text { Mature form on } \\
\text { miRNA array }\end{array}$ & $\begin{array}{l}\text { HF } \\
\text { Expression }\end{array}$ & $\begin{array}{l}\text { \# of uniquely } \\
\text { correlated genes }\end{array}$ \\
\hline \multirow[t]{2}{*}{ miR-31 } & \multirow{2}{*}{$\begin{array}{l}\text { Inhibits anagen development by } \\
\text { regulating gene expression programmes } \\
\text { and alters hair shaft formation in mice }\end{array}$} & \multirow[t]{2}{*}{ Mardaryev AN et al., 2010} & hsa-miR-31-5p & $\checkmark$ & 99 \\
\hline & & & hsa-miR-31-3p & $\checkmark$ & - \\
\hline \multirow[t]{3}{*}{ miR-24 } & \multirow{3}{*}{$\begin{array}{l}\text { Overexpression is associated with } \\
\text { reduced proliferation and premature } \\
\text { HF-keratinocyte differentiation in mice }\end{array}$} & \multirow[t]{3}{*}{ Amelio I et al., 2013} & hsa-miR-24-3p & $\checkmark$ & 103 \\
\hline & & & hsa-miR-24-1-5p & $\checkmark$ & - \\
\hline & & & hsa-miR-24-2-5p & $\checkmark$ & 5 \\
\hline \multirow[t]{2}{*}{ miR-106a } & \multirow{2}{*}{$\begin{array}{l}\text { Upregulated in balding human DPC in } \\
\text { comparison to nonbalding DPCs }\end{array}$} & \multirow[t]{2}{*}{ Goodarzi HR et al., 2012} & hsa-miR-106a-5p & $\checkmark$ & 53 \\
\hline & & & hsa-miR-106a-3p & $x$ & - \\
\hline \multirow[t]{2}{*}{ miR-22 } & \multirow{2}{*}{$\begin{array}{l}\text { Overexpression in mice is associated with } \\
\text { hair loss due to anagen-to-catagen transition } \\
\text { and knockout in mice is associated with } \\
\text { delayed catagen entry and accelerated } \\
\text { telogen-to-anagen transition }\end{array}$} & \multirow[t]{2}{*}{ Yuan S et al., 2015} & hsa-miR-22-5p & $\checkmark$ & - \\
\hline & & & hsa-miR-22-3p & $\checkmark$ & \\
\hline \multirow[t]{3}{*}{ miR-125b } & \multirow{3}{*}{$\begin{array}{l}\text { Represses HF stem cell differentiation in mice; } \\
\text { significantly upregulated in balding human } \\
\text { DPCs in comparison to nonbalding DPCs }\end{array}$} & \multirow{3}{*}{$\begin{array}{l}\text { Zhang L et al., 2011; } \\
\text { Goodarzi HR et al., } 2012\end{array}$} & hsa-miR-125b-5p & $\checkmark$ & - \\
\hline & & & hsa-miR-125b-1-3p & $x$ & \\
\hline & & & hsa-miR-125b-2-3p & $\checkmark$ & \\
\hline miR-137 & $\begin{array}{l}\text { Involved in murine HF pigmentation } \\
\text { (melanogenesis) }\end{array}$ & Dong C et al., 2012 & hsa-miR-137 & $x$ & - \\
\hline \multirow[t]{2}{*}{ miR-205 } & \multirow{2}{*}{$\begin{array}{l}\text { Essential for development of HF stem cell } \\
\text { proliferation during murine embryonic skin } \\
\text { development }\end{array}$} & \multirow[t]{2}{*}{ Wang D et al., 2013} & hsa-miR-205-5p & $\checkmark$ & - \\
\hline & & & hsa-miR-205-3p & $\checkmark$ & \\
\hline \multirow[t]{2}{*}{ miR-214 } & \multirow{2}{*}{$\begin{array}{l}\text { Controls Wnt pathway and } \beta \text {-catenin } \\
\text { expression in murine embryonic HF } \\
\text { development }\end{array}$} & \multirow[t]{2}{*}{ Ahmed Ml et al., 2014} & hsa-miR-214-5p & $x$ & - \\
\hline & & & hsa-miR-214-3p & $x$ & \\
\hline \multirow[t]{2}{*}{ miR-221 } & \multirow{2}{*}{$\begin{array}{l}\text { Upregulated in balding human DPCs in } \\
\text { comparison to nonbalding DPCs }\end{array}$} & \multirow[t]{2}{*}{ Goodarzi HR et al., 2012} & hsa-miR-221-5p & $\checkmark$ & - \\
\hline & & & hsa-miR-221-3p & $\checkmark$ & 1 \\
\hline \multirow[t]{2}{*}{ miR-410 } & \multirow{2}{*}{$\begin{array}{l}\text { Upregulated in balding human DPC in } \\
\text { comparison to nonbalding DPCs }\end{array}$} & \multirow[t]{2}{*}{ Goodarzi HR et al., 2012} & hsa-miR-410-5p & $x$ & - \\
\hline & & & hsa-miR-410-3p & $x$ & \\
\hline
\end{tabular}

HF hair follicle, DPCs dermal papilla cells, \# number

Pathway enrichment of, and protein-protein interactions (PPIs) between, miRNA target genes

For all significantly correlated target genes, testing for pathway enrichment was performed using the Ingenuity Pathway Analysis software (IPA, Qiagen, Hilden, Germany, accessed 31 March 2016); and the Protein ANalysis THrough Evolutionary Relationship database (PANTHER, version 11.1, http://pantherdb.org/, accessed 2nd December 2016) [10]. Only pathways with $\geq 3$ annotated genes and a $P$-value based on right tailed Fisher's exact test $<0.05$ (IPA) were taken into account.

PPIs were investigated using the Search Tool for the Retrieval of Interacting Genes/Proteins (STRING, version 10, http://string-db.org, accessed 2nd December 2016) [11].

\section{miRNA target prediction}

The miRWalk2.0 (http://zmf.umm.uni-heidelberg.de/ apps/zmf/mirwalk2, accessed 11 March 2016) [12]; and the TargetScan7.0 (http://targetscan.org, accessed 2nd December 2016) [13] algorithms were used to search for predicted and validated target genes of the expressed candidate miRNAs. Only genes that were predicted by the miRWalk algorithm and three additional implemented databases, or that were predicted to target a conserved site in TargetScan, were taken into account.

\section{Results}

Seven of the ten candidate miRNAs were expressed in both the frontal an occipital HF samples. The strongest mean $\log _{2}$ expression ( $\log _{2}$ value) was found for miR-205 $\left(\log _{2} \_\right.$value $\left.=3.73 \pm 0.01\right)$, and miR-24 $\left(\log _{2} \_\right.$value $=3.69 \pm$ $0.03)$. Using the present criteria, no expression was observed for miR-137 ( $\log _{2}$ value $\left.=-1.77 \pm 1.72\right)$; miR-214 $\left(\log _{2} \_\right.$value $\left.=1.50 \pm 0.56\right)$; or miR-410 ( $\log _{2} \_$value $=-1.08$ \pm 0.61 ) (data not shown).

To investigate the function of these seven miRNAs, and to identify their target genes in the human HF, a correlation analysis of intrasample mean miRNA and mean mRNA expression was performed. Significant correlation between miRNA and mRNA expression was 
observed for miR-24, miR-31, miR-106a, and miR-221. For miR-24 (i.e., miR-24-3p, miR-24-2-5p), a significant correlation was found with 106 genes: $n=74$, negatively correlated (neg. cor.); and $\mathrm{n}=32$, positively correlated (pos. cor.). The two most significantly correlated genes were COL5A2 (Collagen, Type V, Alpha 2; $r=-0.92, P_{\text {adj }}=1.70 \times 10^{-5}$ ); and SERPING1 (Serpin Family G Member $\left.1 ; r=-0.86, P_{\text {adj }}=8.77 \times 10^{-4}\right)$. For miR-31, a total of 99 genes (53 neg. cor. and 46 pos. cor.) were identified. Here, the two most significantly correlated genes were FAM178A (SMC5-SMC6 complex localisation factor $\left.2 ; r=-0.90, P_{\text {adj }}=1.51 \times 10^{-4}\right)$; and PLAA (Phospholipase A2-Activating Protein; $r=$ $\left.0.89, P_{\text {adj }}=1.82 \times 10^{-4}\right)$. MiR-106a expression was correlated with a total of 53 genes (29 neg. cor. and 24 pos. cor.). Here, the two most significantly correlated genes were UST (Uronyl-2-Sulfotransferase; $r=-0.86$, $\left.P_{\text {adj }}=8.77 \times 10^{-4}\right)$; and COL5A2 $\left(r=-0.85, P_{\text {adj }}=8.77 \times 10^{-4}\right)$ (Additional file 1: Table S1). For miR-221, correlation was found with a single gene - RPRD2 (Regulation Of $\mathrm{Nu}$ clear Pre-MRNA Domain Containing 2; $r=-077$. $P_{\text {adj }}=$ $7.59 \times 10^{-3}$ ). A total of 40 genes were targets of more than one miRNA. The largest overlap was found between target genes of miR-31 and miR-106a $(\mathrm{n}=29)$. Ten genes (FZD7, JUN, MEIS2, TAX1BP3, RBM17, SFRP1, TP63, ZCCHC11, COL17A1, SMARCA4) were significantly correlated with miR-24, miR-31, and miR106a (Fig. 1, Additional file 1: Table S1).

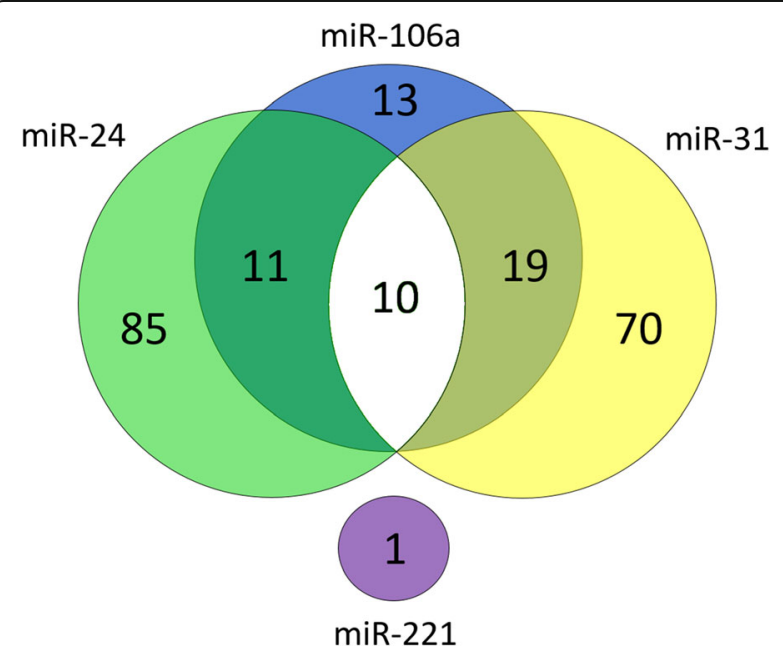

Fig. 1 Overview of all target genes with a significant correlation to miR-24, miR-31, and miR-106a. The largest overlap in target genes was detected for miR-31 and miR-106a $(n=29)$. MiR-31, miR-24 (i.e., miR-24-3p, miR-24-2-5p), and miR-106a shared the following ten target genes: FZD7, JUN, MEIS2, TAXIBP3, RBM17, SFRP1, TP63, SMARCA4, COL17A1, and ZCCHC11. The same ten target genes were shared between miR-31 and miR-24. MiR-24 and miR-106a shared a total of 21 target genes. No overlap was found for miR-221 and the three remaining miRNAs
In the investigation of a potential enrichment of miRNA target genes in biological pathways, IPA revealed the strongest enrichment of the respective target genes in 'Hepatic Fibrosis/Hepatic Stellate Cell Activation' (miR-24), and 'JAK/STAT Signalling' (miR-31 and miR106a). In the PANTHER analysis, 'Integrin Signalling' was the top pathway for the target genes of miR-24, miR-31 and miR-106a. An overview of all identified pathways is provided in Additional file 1: Table S2.

In the miRWalk2.0 [12] and TargetScan7.0 [13] analyses, $40 \%, 62 \%$, and $42 \%$ respectively of the identified target genes for miR-24, miR-31 and miR-106a were not predicted by either tool. The single target gene of miR-221 was predicted by miRWalk only (Additional file 1: Table S3).

The STRING [11] database query revealed numerous interactions between the miRNA-specific-, shared- and all target genes of all four miRNAs. In all PPI-networks, an interaction was observed between JUN and FZD7 via SFRP1 (Fig. 2, Additional file 2: Figure S2).

\section{Discussion}

The present study involved comprehensive analysis in the human HF of ten miRNAs previously implicated in hair biology [7, 14]. Expression profiling confirmed the expression of seven of the ten candidate miRNAs, suggesting that these miRNAs may indeed play a role in human hair biology. For miR-24, miR-31, and miR-106a several target genes and pathways of interest were identified (Table 1).

The highest number of target genes was identified for miR-24. Previous research has identified miR-24 as an anti-proliferative miRNA, which promotes keratinocyte differentiation via the modulation of actin filaments [15], and plays a role in hair morphogenesis [6]. For miR-24 (i.e., miR-24-3p, miR-24-2-5p), correlation analysis revealed a total of 106 unique target genes. These include the miRWalk2.0 predicted target ITGB1, which encodes the integrin $\beta-1$ subunit and has been subject to extensive investigation with respect to skin and hair homeostasis (reviewed in Rippa et al., 2013 [16]). The present pathway analysis also revealed an enrichment of miR-24 target genes in 'Integrin Signalling'. These results suggest that integrin signalling is an essential pathway for keratinocyte differentiation in the human HF, and that this is controlled by miR-24. Furthermore, significant correlations with miR-24 expression were observed for six collagen genes. In descending order of significance, these were: COL5A2, COL17A1, COL4A6, COL4A5, COL18A1 and COL4A1. The respective gene products also form a dense PPI-network (Fig. 2). Previous functional studies have demonstrated hair coat thinning and abnormal HF morphogenesis in mice that overexpress miR-24 in basal keratinocytes. These mice display shorter, misangled, and wavy HFs [6]. A similar hair phenotype is seen in 


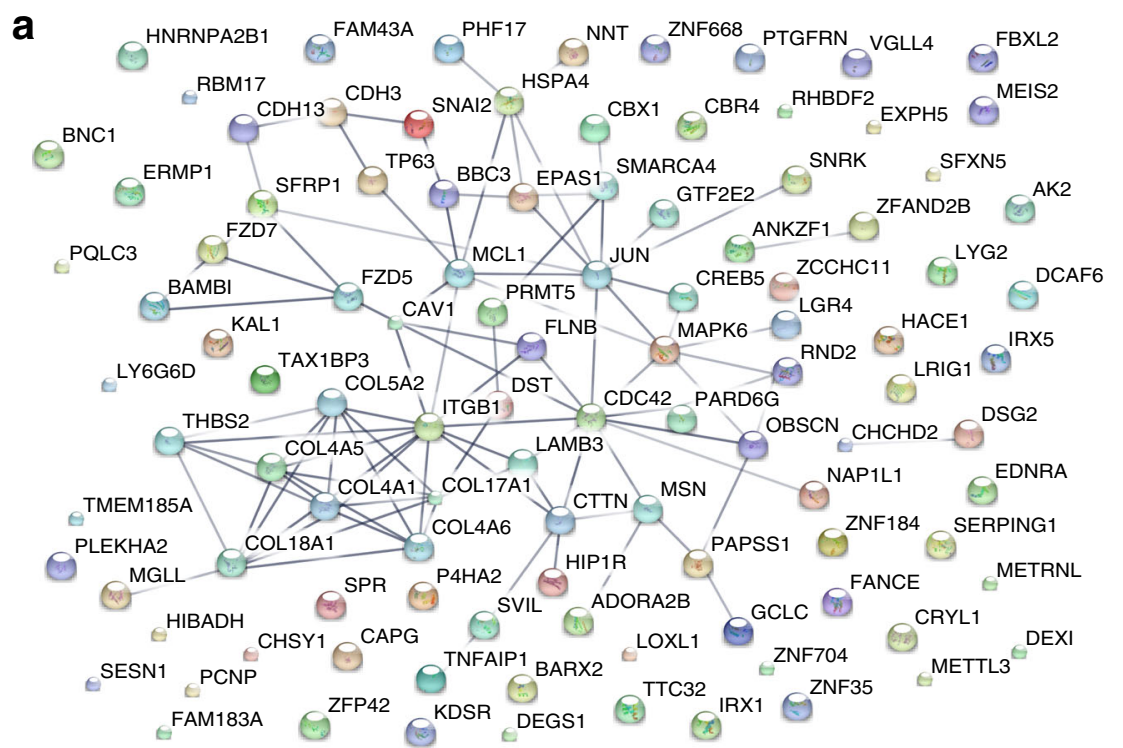

b

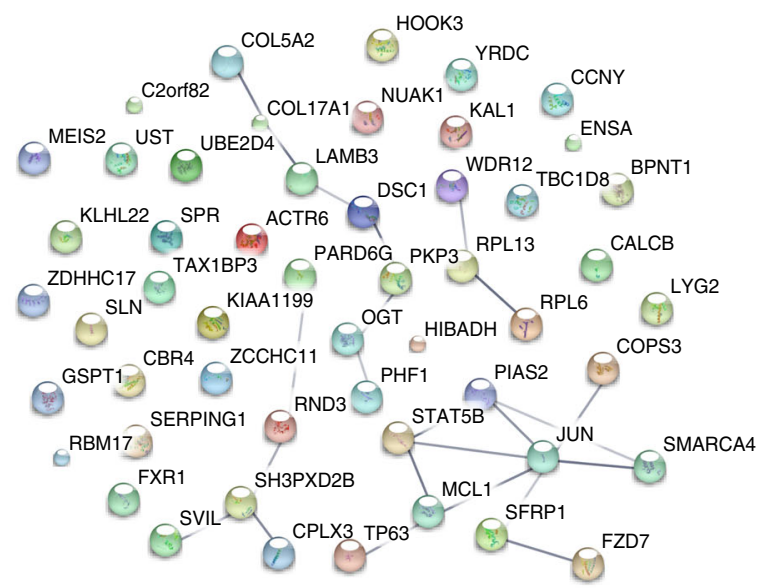

C

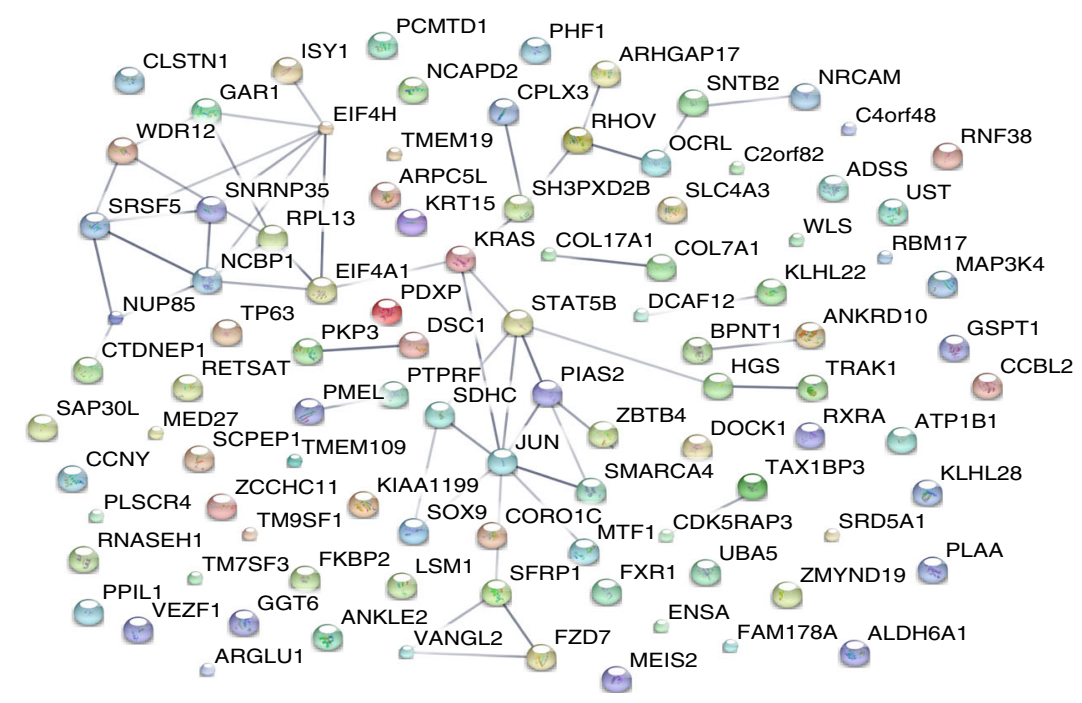

Fig. 2 STRING protein-protein interaction (PPI) query. PPIs of significantly correlated target genes a miR-24; b miR-106a; and $\mathbf{c}$ miR-31. Connecting lines represent confidence interactions according to the STRING database. The genes JUN, SFRPI, and FZD7 were targets of all three miRNAs and show a consistent PPI in combination with other miRNA-specific target proteins 
patients with the chromosome 2q32 deletion syndrome, whose clinical features include thin, sparse, woolly, and slowly growing scalp hair $[17,18]$. Interestingly, the affected 2q32 chromosomal region includes COL5A2. Another collagen gene, Col17a1, is reported to be essential for HF stem cell maintenance [19] and ageassociated HF miniaturisation and thinning, as mediated by COL17A1 proteolysis [20]. Moreover, COL17A1 deficiency is associated with junctional epidermolysis bullosa, a severe skin disease characterised by hair loss [21]. Taken together, these data suggest that miR-24 is an important regulator of hair morphogenesis and maintenance, which achieves its effect via the control of integrin and collagen signalling. The present study also detected an enrichment of miR-24 target genes in the hormone signalling cascades 'Gonadotropin Releasing Hormone (GnRH) Receptor Pathway', and 'Androgen Signalling'. Whereas androgen signalling is essential for hair biology and has been shown to regulate hair growth and cycling at different body sites [22], GnRH signalling antagonises androgen receptor signalling at androgen-sensitive body sites in women, and GnRH antagonists are an effective treatment for hirsutism [23, 24]. Research is warranted to determine whether these hormone pathways also play a role in keratinocyte differentiation.

Research has shown that miR-31 is responsible for both anagen inhibition and normal hair shaft formation [4]. The present analyses identified a total of 99 target genes that may act downstream of miR-31 in these processes. These include Retinoid X Receptor Alpha (RXRA), a nuclear receptor which is highly expressed in skin and in HF outer root sheath (ORS) keratinocytes $[25,26]$. In mice, ablation of Rxra in the skin leads to HF degeneration and subsequent hair loss [27], while conditional knockout in epidermal and ORS keratinocytes results in altered anagen initiation [28]. These findings underline the role of $R X R A$ in HF maintenance and hair cycle control. Interestingly, target genes of miR-31 were enriched in PPAR and RAR/ $R X R A$ signalling, thus supporting the hypothesis that $R X R A$-mediated signalling is important for the control of anagen initiation. Moreover, miR-31 target genes were enriched in PDGF (Platelet-Derived Growth Factor), adipogenesis, and JAK/STAT signalling, which have been implicated previously in the control of the HF cycle [29-33]. Studies in murine HFs have demonstrated that several PDGF isoforms induce and maintain murine anagen HFs [31]. Furthermore, PDGF signalling may contribute to the essential role of immature adipocytes in anagen induction [34]. A recent study identified JAK/STAT signalling as a promising therapeutic target for the treatment of hair loss disorders. Here, topical application of JAK/STAT inhibitors to the shaved back skin of mice led to rapid anagen induction [33]. Collectively, the identified target genes and pathways indicate that miR-31 is a potent cross-species inhibitor of the anagen phase. However, functional studies are required to confirm the interaction between miR-31 and these pathways, and to elucidate their role in anagen control in the human HF.

The third miRNA to show significant mRNA correlations in the present analyses, miR-106a, is reported to be upregulated in the balding, as compared to the nonbalding, DPCs of males with MPB, which suggests that it may be implicated in MPB pathobiology [7]. Although none of the 53 identified target genes of miR-106a have yet been associated with MPB, two building blocks of the desmosome - Plakophilin 3 (PKP3) and Desmocollin 1 (DSC1), are reported to play a role in HF morphogenesis [35]. Pkp3 deficient mice develop an abnormal hair coat and secondary alopecia [36]. Although Dsc1 deficient mice show normal HF cycling and structures until the age of four weeks, they develop alopecia and HF degeneration in later life [37]. Moreover, one of the pathways identified in the present study was 'WNT Signalling, which is of key importance in terms of HF development and cycling [38-41]. Interestingly, genetic evidence is available for the involvement of WNT signalling in MPB development. Heilmann et al. reported that a single nucleotide polymorphism (rs7349332) located intronically in WNT10A was associated with MPB risk $\left(P \leq 5 \times 10^{-8}\right)$ and resulted in reduced WNT10A expression in HFs of risk allele carriers [42]. The present analyses therefore provide strong support for the hypothesis that miR-106a contributes to MPB development via WNT signalling and that the regulation of cell-cell adhesion may be an important factor in MPB.

Intriguingly, ten of the identified target genes were shared between miR-31, miR-24, and miR-106a, suggesting that they may be critical points in the signalling cascades that control HF biology. The overlapping target genes FZD7, SFRP1, and TAX1BP3 are involved in WNT/ $\beta$-catenin signalling, which is an important biological pathway for HF development and maintenance [43-46]. The WNT receptor FZD7 mediates canonical and noncanonical signalling $[47,48]$, while SFRP1 and TAX1BP3 are reported as WNT antagonists. The respective proteins exert their effects via direct interaction with WNT or FZD proteins [49] and binding to $\beta$-catenin [50], respectively. Another interesting shared target gene is TP63, since one characteristic of $p 63$ knockout mice is the absence of HFs [51]. SMARCA4 is a component of the chromatin remodelling complex, and knock-out experiments in murine bulge cells showed that it is required for hair regeneration and anagen progression [52]. The role of COL17A1 in hair biology was discussed earlier. The four remaining overlapping target genes have not yet been associated with HF biology. The gene RBM17 is reported to be involved in mRNA splicing [53], JUN belongs to the AP-1 
transcription factor family, and is involved in many fundamental cell processes including proliferation, differentiation, and apoptosis and plays an essential role in skin development and the differentiation of epidermal keratinocytes [54-59]. MEIS2 encodes a TALE homeobox protein, which is a highly conserved transcription factor, and $\mathrm{ZCCHC11}$ is a zinc finger containing RNA uridyltransferase. Taken together, these results underline the importance of WNT signalling in hair biology and suggest that miRNAs are critical regulators of WNT and TP63 signalling in the human HF.

In addition to these ten shared genes, a total of 30 genes were targeted by two miRNAs. These therefore represent further promising candidate genes, which may impact key functions in healthy hair biology and the pathobiology of hair loss disorders.

According to the STRING database, numerous interactions exist between the identified target genes of each candidate miRNA, and among the 40 shared miRNA target genes. This indicates that these miRNAs are (in)directly involved in various regulatory networks. Notably, all of these networks contain an indirect interaction between JUN and FZD7 via SFRP1, suggesting that these genes may play a pivotal role in the miRNA mediated control of HF cycling, keratinocyte differentiation and MPB development (Fig. 2, Additional file 2: Figure S2).

The present analyses failed to confirm the expression of miR-137, miR-214 and miR-410 in the human HF. While miR-137 has been described in the determination of murine coat colour [5], no data are available concerning the expression pattern of miR-137 in the human HF or skin. Research has shown that miR-214 controls WNT/ $\beta$-catenin signalling in murine embryonic HF development [60]. Further studies are required to determine whether miR-137 is involved in the determination of human hair colour and whether miR-214 plays a role in human HF embryogenesis. MiR-410 expression was found almost exclusively in the DPCs of balding vellus HFs [7]. As the present analyses were restricted to nonbalding HFs with sparse DPCs, the failure to detect miR410 expression in the present samples may point to a very specific role for miR-410 during MPB pathogenesis. Moreover, no significant correlation was found with mRNA expression for miR-22, miR-125b, or miR-205. This may be attributable to limited power of our sample $(n=24)$ to detect smaller regulatory effects.

\section{Conclusions}

In conclusion, the present systematic investigation of the expression of ten miRNAs previously implicated in hair biology and the identification of their target genes, pathways, and regulatory networks provides novel insights into the biological mechanisms that control human HF cycling, HF keratinocyte differentiation, and MPB pathogenesis. Further analyses in larger samples and detailed functional follow up investigations, such as the precise miRNA localisation in the human HF and their expression profile during different hair cycle stages, are now warranted to confirm these findings and to identify additional target genes and regulatory interactions. Increased sample sizes will also allow genome-wide investigations and thus the identification of additional hairrelevant miRNAs, as well as their target genes and regulated pathways. This research will facilitate understanding of human hair (patho-) biology.

\section{Additional files}

Additional file 1: Tables S1-S4. Significantly correlated target genes of miR-24, miR-31, miR-106a, and miR-221. Table S2. Overview of pathways identified via IPA and PANTHER. Table S3. Prediction of significantly correlated target genes of miR-24, miR-31, miR-106a, and miR-221. Table S4. Intra-individual mRNA and miRNA correlations. (XLSX $101 \mathrm{~kb}$ )

Additional file 2: Figures S1-S2. Figure S1. Single tissue analysis of miRNA Expression in the human hair follicle. Figure S2. STRING query. (PDF $258 \mathrm{~kb}$ )

\section{Abbreviations}

DPC: Dermal papilla cell; HF: Hair follicle; IPA: Ingenuity pathway analysis; miRNA/miR: MicroRNA; MPB: Male pattern baldness; PANTHER: Protein analysis through evolutionary relationship; PPI: Protein-protein interaction; STRING: Search tool for the retrieval of interacting genes/proteins

\section{Acknowledgments \\ The authors thank the study participants for their cooperation. We thank Christine Schmael for her revision of the manuscript. MMN is a member of the Deutsche Forschungsgemeinschaft (DFG) Excellence Cluster ImmunoSensation.}

Funding

The study was supported by the BONFOR programme of the Medical Faculty of the University of Bonn.

\section{Availability of data and materials}

The datasets supporting the conclusions of this article are included within the manuscript and its supporting material. The generated microarray datasets are available from the corresponding author upon request.

\section{Authors' contributions}

$\mathrm{TA}$, LMH collected the samples. NF, MHR, CSB, LMH, SHH designed and performed the experiments. $\mathrm{LMH}, \mathrm{SHH}$ and MMN prepared the manuscript. All authors read and approved the final manuscript.

\section{Competing interests}

The author(s) declare that they have no competing interests.

Consent for publication

Not applicable.

Ethics approval and consent to participate

The study was approved by the ethics committee of the University of Bonn. Written informed consent was obtained from all participants prior to inclusion. The study was conducted in accordance with the Declaration of Helsinki.

\section{Author details}

${ }^{1}$ Institute of Human Genetics, University of Bonn, Sigmund-Freud-Str. 25, 53127 Bonn, Germany. ${ }^{2}$ Department of Genomics, Life and Brain Center, University of Bonn, Sigmund-Freud-Str. 25, 53127 Bonn, Germany. ${ }^{3}$ Human Genomics Research Group, Department of Biomedicine, University of Basel, Hebelstrasse 20, 4031 Basel, Switzerland. 


\section{Received: 17 August 2016 Accepted: 11 February 2017}

\section{Published online: 22 February 2017}

\section{References}

1. Millar SE. Molecular mechanisms regulating hair follicle development. J Invest Dermatol. 2002;118:216-25.

2. Schneider MR, Schmidt-Ullrich R, Paus R. The hair follicle as a dynamic miniorgan. Curr Biol. 2009;19:R132-42.

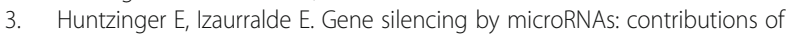
translational repression and mRNA decay. Nat Rev Genet. 2011;12:99-110.

4. Mardaryev AN, Ahmed MI, Vlahov NV, et al. Micro-RNA-31 controls hair cycle-associated changes in gene expression programs of the skin and hair follicle. FASEB J. 2010;24:3869-81.

5. Dong $C$, Wang $H$, Xue $L$, et al. Coat color determination by miR-137 mediated down-regulation of microphthalmia-associated transcription factor in a mouse model. RNA. 2012;18:1679-86.

6. Amelio I, Lena a M, Bonanno E, et al. miR-24 affects hair follicle morphogenesis targeting Tcf-3. Cell Death Dis. 2013;4:e922.

7. Goodarzi HR, Abbasi A, Saffari M, et al. Differential expression analysis of balding and nonbalding dermal papilla microRNAs in male pattern baldness with a microRNA amplification profiling method. Br J Dermatol. 2012;166:1010-6.

8. Barbosa-Morais NL, Dunning MJ, Samarajiwa SA, et al. A re-annotation pipeline for Illumina BeadArrays: improving the interpretation of gene expression data. Nucleic Acids Res. 2010;38:e17.

9. Pearson K. Determination of the coefficient of correlation. Science. 1909;30:23-5.

10. Mi H, Muruganujan A, Thomas PD. PANTHER in 2013: modeling the evolution of gene function, and other gene attributes, in the context of phylogenetic trees. Nucleic Acids Res. 2013;41:D377-86.

11. Szklarczyk D, Jensen $L$. Protein-protein interaction databases. Methods Mol Biol. 2015;1278:39-56.

12. Dweep H, Gretz N. miRWalk2.0: a comprehensive atlas of microRNA-target interactions. Nat Methods. 2015;12:697.

13. Agarwal V, Bell GW, Nam J-W, Bartel DP. Predicting effective microRNA target sites in mammalian mRNAs. Elife 2015; 4. doi:10.7554/eLife.05005

14. Andl T, Botchkareva NV. MicroRNAs (miRNAs) in the control of HF development and cycling: The next frontiers in hair research. Exp Dermatol. 2015;24:821-6

15. Amelio I, Lena AM, Viticchiè $G$, et al. miR-24 triggers epidermal differentiation by controlling actin adhesion and cell migration. J Cell Biol. 2012;199:347-63.

16. Rippa AL, Vorotelyak EA, Vasiliev AV, Terskikh W. The role of integrins in the development and homeostasis of the epidermis and skin appendages. Acta Naturae. 2013;5:22-33.

17. Van Buggenhout G, Van Ravenswaaij-Arts C, Mc Maas N, et al. The del(2)(q32.2q33) deletion syndrome defined by clinical and molecular characterization of four patients. Eur J Med Genet. 2005;48:276-89.

18. Rifai L, Port-Lis M, Tabet A-C, et al. Ectodermal dysplasia-like syndrome with mental retardation due to contiguous gene deletion: further clinical and molecular delineation of del(2q32) syndrome. Am J Med Genet A. 2010; 152A:111-7.

19. Tanimura $S$, Tadokoro $Y$, Inomata $K$, et al. Hair follicle stem cells provide a functional niche for melanocyte stem cells. Cell Stem Cell. 2011:8:177-87.

20. Matsumura $H$, Mohri $Y$, Binh NT, et al. Hair follicle aging is driven by transepidermal elimination of stem cells via COL17A1 proteolysis. Science. 2016;80(351):aad4395.

21. Darling TN, Bauer JW, Hintner H, Yancey KB. Generalized atrophic benign epidermolysis bullosa. Adv Dermatol. 1997;13:87-120.

22. Inui S, Itami S. Androgen actions on the human hair follicle: perspectives. Exp Dermatol. 2013;22:168-71.

23. Hohl A, Ronsoni MF, de Oliveira M. Hirsutism: diagnosis and treatment. Arc Bras Endocrinol Metabol. 2014;58:97-107.

24. Andreyko JL, Monroe SE, Jaffe RB. Treatment of hirsutism with a gonadotropin-releasing hormone agonist (nafarelin). J Clin Endocrinol Metab. 1986;63:854-9.

25. Fisher GJ, Talwar HS, Xiao JH, et al. Immunological identification and functional quantitation of retinoic acid and retinoid $X$ receptor proteins in human skin. J Biol Chem. 1994;269:20629-35.

26. Reichrath J, Münssinger $T$, Kerber $A$, et al. In situ detection of retinoid-X receptor expression in normal and psoriatic human skin. Br J Dermatol. 1995;133:168-75.
27. Ghyselinck NB, Chapellier B, Calléja C, et al. Genetic dissection of retinoic acid function in epidermis physiology. Ann Dermatologie vénéréologie. 2002;129:793-9.

28. Li M, Chiba H, Warot $X$, et al. RXR-alpha ablation in skin keratinocytes results in alopecia and epidermal alterations. Development. 2001;128:675-88.

29. Karlsson L, Bondjers C, Betsholtz C. Roles for PDGF-A and sonic hedgehog in development of mesenchymal components of the hair follicle. Development. 1999;126:2611-21.

30. Kamp H, Geilen CC, Sommer C, Blume-Peytavi U. Regulation of PDGF and PDGF receptor in cultured dermal papilla cells and follicular keratinocytes of the human hair follicle. Exp Dermatol. 2003;12:662-72.

31. Tomita Y, Akiyama M, Shimizu H. PDGF isoforms induce and maintain anagen phase of murine hair follicles. J Dermatol Sci. 2006;43:105-15.

32. Schmidt B, Horsley V. Unravelling hair follicle-adipocyte communication. Exp Dermatol. 2012;21:827-30

33. Harel S, Higgins CA, Cerise JE, et al. Pharmacologic inhibition of JAK-STAT signaling promotes hair growth. Sci Adv. 2015;1:1-13.

34. Festa E, Fretz J, Berry R, et al. Adipocyte lineage cells contribute to the skin stem cell niche to drive hair cycling. Cell. 2011;146:761-71.

35. Nekrasova O, Green KJ. Desmosome assembly and dynamics. Trends Cell Biol. 2013;23:537-46.

36. Sklyarova T, Bonné S, D'Hooge $\mathrm{P}$, et al. Plakophilin-3-deficient mice develop hair coat abnormalities and are prone to cutaneous inflammation. J Invest Dermatol. 2008;128:1375-85.

37. Chidgey M, Brakebusch C, Gustafsson E, et al. Mice lacking desmocollin 1 show epidermal fragility accompanied by barrier defects and abnormal differentiation. J Cell Biol. 2001;155:821-32.

38. Millar SE, Willert K, Salinas PC, et al. WNT Signaling in the Control of Hair Growth and Structure. Dev Biol. 1999;207:133-49.

39. Reddy S, Andl T, Bagasra A, et al. Characterization of Wnt gene expression in developing and postnatal hair follicles and identification of Wnt5a as a target of Sonic hedgehog in hair follicle morphogenesis. Mech Dev. 2001;107:69-82.

40. Andl T, Reddy ST, Gaddapara T, Millar SE. WNT Signals Are Required for the Initiation of Hair Follicle Development. Dev Cell. 2002;2:643-53.

41. Shimizu H, Morgan BA. Wnt Signaling through the $\beta$-Catenin Pathway Is Sufficient to Maintain, but Not Restore, Anagen-Phase Characteristics of Dermal Papilla Cells. J Invest Dermatol. 2004;122:239-45.

42. Heilmann S, Kiefer AK, Fricker N, et al. Androgenetic alopecia: identification of four genetic risk loci and evidence for the contribution of WNT signaling to its etiology. J Invest Dermatol. 2013;133:1489-96.

43. Huelsken J, Vogel R, Erdmann B, et al. $\beta$-Catenin Controls Hair Follicle Morphogenesis and Stem Cell Differentiation in the Skin. Cell. 2001; 105:533-45.

44. Chen D, Jarrell A, Guo C, et al. Dermal $\beta$-catenin activity in response to epidermal Wnt ligands is required for fibroblast proliferation and hair follicle initiation. Development. 2012;139:1522-33.

45. Choi YS, Zhang $Y, X u$ M, et al. Distinct functions for Wnt/ $\beta$-catenin in hair follicle stem cell proliferation and survival and interfollicular epidermal homeostasis. Cell Stem Cell. 2013;13:720-33.

46. Tsai S-Y, Sennett R, Rezza A, et al. Wnt/ $\beta$-catenin signaling in dermal condensates is required for hair follicle formation. Dev Biol. 2014:385:179-88.

47. Bhanot $P$, Brink $M$, Samos $C H$, et al. A new member of the frizzled family from Drosophila functions as a Wingless receptor. Nature. 1996;382:225-30.

48. Ueno K, Hirata H, Hinoda Y, Dahiya R. Frizzled homolog proteins, microRNAs and Wnt signaling in cancer. Int J cancer. 2013;132:1731-40.

49. Kawano Y. Secreted antagonists of the Wnt signalling pathway. J Cell Sci. 2003;116:2627-34

50. Kanamori M, Sandy P, Marzinotto S, et al. The PDZ protein tax-interacting protein-1 inhibits beta-catenin transcriptional activity and growth of colorectal cancer cells. J Biol Chem. 2003;278:38758-64.

51. Mills AA, Zheng $B$, Wang $X J$, et al. p63 is a p53 homologue required for limb and epidermal morphogenesis. Nature. 1999:398:708-13.

52. Xiong Y, Li W, Shang C, et al. Brg1 governs a positive feedback circuit in the hair follicle for tissue regeneration and repair. Dev Cell. 2013;25:169-81.

53. Lallena MJ, Chalmers KJ, Llamazares S, et al. Splicing regulation at the second catalytic step by Sex-lethal involves 3' splice site recognition by SPF45. Cell. 2002;109:285-96.

54. Jochum W, Passegué E, Wagner EF. AP-1 in mouse development and tumorigenesis. Oncogene. 2001;20:2401-12. 
55. Rossi A, Jang Sl, Ceci R, et al. Effect of AP1 transcription factors on the regulation of transcription in normal human epidermal keratinocytes. Invest Dermatol. 1998;1 10:34-40.

56. Angel P, Szabowski A, Schorpp-Kistner M. Function and regulation of AP-1 subunits in skin physiology and pathology. Oncogene. 2001;20:2413-23.

57. Mehic D, Bakiri L, Ghannadan M, et al. Fos and jun proteins are specifically expressed during differentiation of human keratinocytes. J Invest Dermatol. 2005;124:212-20.

58. Zenz R, Wagner EF. Jun signalling in the epidermis: From developmental defects to psoriasis and skin tumors. Int J Biochem Cell Biol. 2006;38:1043-9.

59. Han B, Rorke EA, Adhikary G, et al. Suppression of AP1 transcription factor function in keratinocyte suppresses differentiation. PLoS One. 2012;7:e36941.

60. Ahmed Ml, Alam M, Emelianov VU, et al. MicroRNA-214 controls skin and hair follicle development by modulating the activity of the Wnt pathway. J Cell Biol. 2014;207:549-67.

Submit your next manuscript to BioMed Central and we will help you at every step:

- We accept pre-submission inquiries

- Our selector tool helps you to find the most relevant journal

- We provide round the clock customer support

- Convenient online submission

- Thorough peer review

- Inclusion in PubMed and all major indexing services

- Maximum visibility for your research

Submit your manuscript at www.biomedcentral.com/submit
Biomed Central 